\title{
REVIEW ARTICLE QUALITY CONTROL IN ECHOCARDIOGRAPHY REPORTING (PART
}

A)

\author{
Imran Hameed ${ }^{1}$ \\ ${ }^{1}$ Anklesaria Nursing Home, Karachi, Pakistan
}

For cardiac evaluation echocardiography is of immense importance. Easy availability, low cost, and portability lands it in the hands of novices at times. It has a learning curve and expertise must be obtained to keep the standard of reports high and reliable. The referring physician must be fully conversant with the indications of echocardiography. The echocardiographic machine should deliver images of high resolution and fully equipped with all the basic modalities. Availability of 3D (3-dimensional) imaging, tissue synchronization imaging and strain analysis are added advantages. Preliminary data of patient must be collected and the study should be recorded for off-line analysis. Finally, the findings should be narrated on a proforma in the form of a standardized report showing all the relevant features, especially directed to the query of referring physician, thus completing the loop.

Keywords: Transthoracic echocardiography, Echocardiography report and Quality control

Citation: Hameed I. Quality Control in Echocardiography Reporting (Part A). Pak Heart J. 2021;54(04):292-299. DOI: https://doi.org/10.47144/phj.v54i4.2119

\section{INTRODUCTION}

Quality control measures are of immense importance especially in fields like echocardiography where technical skill should be backed by latest scientific knowledge to produce excellent results.

To assure quality the first step is to have appropriate referral. For this 'appropriate use criteria (AUC)' have been forwarded by various agencies. ${ }^{1,2}$

For 'patient centered' quality control, Ingram TE et al., recommended a four-pronged system for every echocardiography laboratory. ${ }^{3}$ They recommend scrutiny of a set number of recorded cases for: echo quality (acquisition and reporting), reproducibility (consistency and variability), education and customer satisfaction.

Kossaify A et al. recommended "patient selection, conformity to AUC, study performance, interpretation, reporting, competence assessment, CUDS (constructive unit direction and supervision), and QIP (quality improvement project) are essential ingredients to generate a high-quality echocardiographic product with beneficial clinical outcome". ${ }^{4}$

Steeds RP et al. emphasized appropriate use criteria to discourage its excessive use, although trans-thoracic echocardiography (TTE) has reduced diagnostic errors by $50 \%$ in the last twenty years. They conclude, "TTE is operator dependent and it is vital that the test is performed by qualified individuals within proficient departments that monitor quality". 5
Thus, it is quite clear that quality control in echocardiography is immensely important and is a multi-step process requiring vigilance at every step, Figure 1. In this document every step has been explained to ensure 'quality control in echocardiography reporting' by healthcare providers involved in this field.

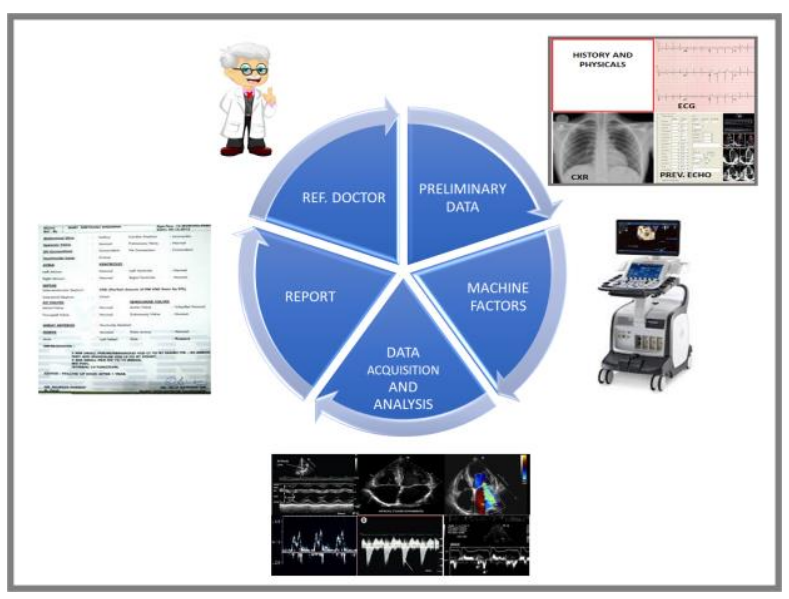

Figure 1: Steps to assure quality control in Echocardiography reporting

MATERIAL AND METHODS: Pub-med, Google scholar and Pakmedinet databases' search revealed 200 studies of which 44 were relevant.

Referral for Echocardiography (ECHO): Knowledge of the referring physician plays key role here. Al-Kaisey et al. reported $77 \%$ appropriate, $20.3 \%$ inappropriate, and $2.7 \%$ uncertain referrals. ${ }^{6}$ Similarly, Patil et al. mentioned $82 \%$ appropriate, 
$12.3 \%$ inappropriate, $5.3 \%$ uncertain, and $0.4 \%$ nonfitting referrals in their study of 1825 subjects. ${ }^{7}$

Vanessa Rameh et al. in 501 patients referred for TTE found that according to 2011 AUC $74.6 \%$ had appropriate indication, whereas the rest were either inappropriate, uncertain or non-fitting. ${ }^{8}$ Metulevicius et al. found $91.8 \%$ appropriate referrals while the rest were inappropriate or uncertain. However, no difference was noted for change of treatment in either group $(\mathrm{p}=0.29){ }^{9}$

Gurzun MM and Ionescu A did a remarkable study in Wales assessing all echo referrals and reports $(n=1070)$, done in the entire country in one week for AUC application, type of center, health care worker, referrals from in/out-patients and the result of abnormal reports found. ${ }^{10}$ They noted that, "major indications were assessment of: cardiac structure and function $(45.7 \%)$, valvular function $(25 \%)$, and hypertension, heart failure, or cardiomyopathy (13.9\%). In-patient requests were more often appropriate than out-patients. The most common inappropriate indication was initial evaluation for a murmur/click, without symptoms/signs of structural heart disease $(2.7 \%)$. The proportions of appropriate requests by specialty was $89 \%$ for medical, $87 \%$ for GPs, $85.3 \%$ for cardiologists, $80.8 \%$ for surgical, and $60 \%$ for cardiac surgeons $(\mathrm{P}<0.05$ for cardiac surgeons); $47.8 \%$ of requests were generated by cardiologists, and abnormalities were detected in $82 \%$ of all scans (37\% minor findings and $45 \%$ major findings), least often in those requested by GPS".

PRELIMINARY DATA: The performing and reporting person for echocardiography must have prestudy knowledge with regard to demographics, clinical findings, ECG and Chest X-ray (CXR). ${ }^{11}$ Review of previous study will greatly facilitate about the progress of disease and making informed decisions. Echocardiography laboratory requirements are:

a) Room should be $12-20 \mathrm{~m}^{2}$, with enough darkness to ensure good image visualization and minimal sound so as to hear doppler signals clearly. Reporting area should be separate. ${ }^{12}$

b) Echo couch should be of adjustable height with space cut-out to make apical views easily.

c) Emergency cart, defibrillator, provision of oxygen supply and suction facility.

d) A single machine should be used at the most for 2500 cases per annum. ${ }^{12}$ Images and clips should be digitally stored in DICOM format. ${ }^{13}$

e) All probes must be cleaned with anti-septic after every study.

f) Ideally a technical staff to record images and a cardiologist for interpretation are needed. It has been proposed that the head of unit should not examine more than 1800 cases per annum. ${ }^{12}$ The recommended level of training (exclusively for TTE) according to COCTAS FORCE require a duration of 9 months with a total of 300 exams performed and 750 interpreted in three levels of three months each. ${ }^{14}$ Dedicated recommendations for echocardiography in ICU have also been forwarded. ${ }^{15}$ Furthermore, for complete training in echocardiography including all modalities have been forwarded by AHA/ACC. ${ }^{16}$

g) Patient should wear loose flexible clothes and an attendant be allowed especially for female patients. ECG gating is a must and provision of respiration monitoring is advisable. ${ }^{17}$ Patient is usually examined in left lateral position.

h) 40 to 45 minutes are required for a study.

MACHINE FACTORS: Echocardiographic machines have evolved with regard to technology immensely, in the last few decades making them more compact, advanced in features and improved in resolution. These are now available in pocket size as well, but all of them don't have the capability for a comprehensive echo exam. A standard machine must have the capability of M-mode, 2-D, color, pulsed wave $(\mathrm{PW})$, continuous wave $(\mathrm{CW})$ and tissue doppler (TD) along with harmonic imaging (HI).

Multi-frequency probe (1-5 MHz) or dedicated probes of low (2-2.5 MHz) and high frequency (3 and greater) should be available. ${ }^{18}$ Pedoff probe availability is a recommended enhanced provision. The foot prints of the probe should be as small as possible $(10-13 \mathrm{~mm})$ so as to fit into the intercostal spaces easily.

Echocardiographic machines must be kept in highest order of working with annual maintenance and no machine older than ten years should be in use. Sound knowledge of the operator to optimize the image from patients of various body habitus and echogenicity is mandatory.

DATA ACQUISITION: Good quality data is acquired by convex phased array transducers for the following modalities.

A. M-mode imaging: It still retains value due to high sampling rate and good temporal resolution. 2D directed M-mode images are utilized for measurements. The alignment during recording of chamber dimensions should be perpendicular to the structure measured otherwise off axis cuts produce errors. During acquisition of Mitral annular plane systolic excursion (MAPSE) and Tricuspid annular plane systolic excursion (TAPSE) the cursor should remain parallel to RV 
free wall and LV lateral wall respectively and on axis with movement of respective annuli.

B. 2D imaging: This is the cornerstone of echocardiography. By adopting following measures, good quality 2D images can be obtained:

1. The area of interest should form the center of image and never off axis.

2. Sector width and image depth should ensure a frame rate of 50 to $70 / \mathrm{sec}$.

3. For ventricular assessment the endocardium should be clearly visible in all the segments during the entire cardiac cycle especially apex and anterior wall as these require additional manipulation for proper visualization. Foreshortening should be avoided. Chordae and papillary muscles are counted as part of ventricular cavity. Contrast should be used if two or more segments for wall motion are not properly visualized. Apical views are taken so that the entire length of LV remains visible along with one third of left atrium. Apex should lie in the angle of the image sector (as ellipsoid and not rounded in normal hearts) and the chambers appear vertical, not slanting. Length of views shouldn't differ by more than $0.5 \mathrm{~cm}$. In apical $2 \mathrm{C}$ view no part of RV should be visible.

4. Right ventricle should always be assessed in RV focused apical view with entire length of $\mathrm{RV}$ visible and no fore-shortening noted.

5. Atrial assessment needs complete visualization and no fore-shortening.

6. Inferior vena cava should be visualized in its maximum diameter.

7. All the views may not be recorded in every patient. Apical (93-99\%) and PS LAX (97\%) are obtained in majority of cases. ${ }^{20}$

C. Color Doppler: Very important, especially with regard to valvular regurgitation and shunt assessment. Measures for good quality color doppler images are:

1. Nyquist limit set around $64 \mathrm{~cm} / \mathrm{s}(50-70 \mathrm{~cm} / \mathrm{s})$.

2. Region of interest (ROI) is kept minimum, enclosing the area of interest. Aortic valve needs smaller ROI whereas Mitral and Tricuspid valves need larger.

3. The formula of BART (blue away red towards) is used.

4. Factors affecting regurgitant jet size are:

a. Regurgitant jet momentum, impingement on wall and entrainment.

b. Nyquist limit and pulse repetition frequency.

c. Color gain, ultrasound frequency and attenuation in far field.

d. Angle of interrogation and orifice geometry. ${ }^{21}$
5. While recording PISA (proximal Isovelocity surface area) for estimation of valve regurgitation the following precautions are needed:

a. Apical 5 chamber (aortic), 4 chamber (mitral and tricuspid), 3 chamber (mitral) or parasternal short axis (PS SAX) (pulmonary) views should be chosen.

b. Valve of interest should be in the center of image, in zoomed view.

c. All the three components of regurgitation i.e., Flow convergence zone, Vena contracta and regurgitation jet should be clearly visible, Figure 2.

d. Baseline is shifted towards regurgitant jet so that a Nyquist limit of $35-40 \mathrm{~cm} / \mathrm{s}$ may be obtained to keep the shape of PISA hemispheric.

e. Color variance is turned off.

f. PISA radius should be taken from the zone of color aliasing (i.e., junction of blue and yellow color) till Vena contracta, Figure 2.

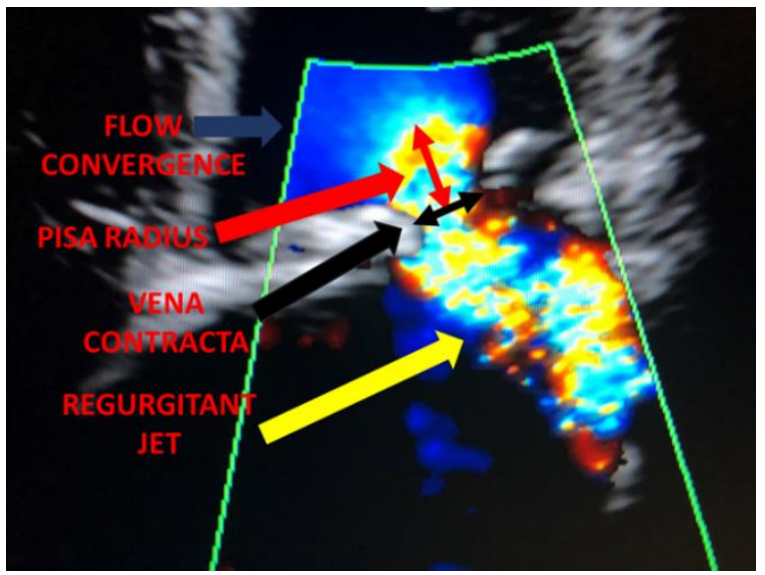

Figure 2: The zones of regurgitation jet through mitral valve

D. Pulsed wave doppler: A good quality PW recording must satisfy:

1. Ultrasound beam aligned parallel to the blood flow.

2. The onset and offset of blood flow should be clear, by using wall filters.

3. A clear spectrum is recorded with sharp peaks or outer rim and clear center, with no feathering or spikes, Figure 3.

4. Sweep speed should be $100 \mathrm{~cm} / \mathrm{s}$ however, for recording respiratory variation in cardiac tamponade or constrictive pericarditis this should be $25 \mathrm{~cm} / \mathrm{s}$. Sample volume should be $1-2 \mathrm{~mm}$ in size for mitral valve and left ventricular outflow tract (LVOT) with low wall filters and signal gain $(100-200 \mathrm{~Hz})$. 
5. For mitral and tricuspid valve, the sample volume should be placed between the tips of leaflets whereas for LV and RV outflow it should be placed just proximal to the valves.

6. For pulmonary vein the sample volume (size 3$4 \mathrm{~mm}$ ) should be placed $1-2 \mathrm{~cm}$ inside the vein interrogated

7. Isovolumic relaxation time (IVRT) is recorded in apical 5C view with Mitral inflow and LV out flow recorded simultaneously.

8. Valsalva records must be obtained for 10 seconds.

9. In sinus rhythm 3 beats and in atrial fibrillation 5 beats are recorded and averaged.

E. Continuous wave doppler: Same quality control measures are adopted as for PW doppler, but here all the velocities are recorded hence the envelope would be homogenous, Figure 3.

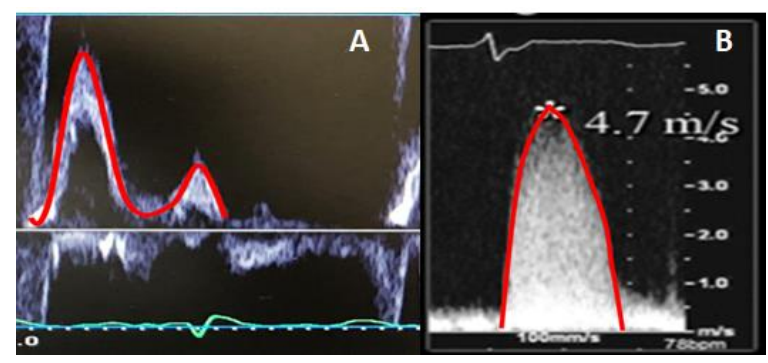

Figure 3: A. PW record shows clear centre and sharp peaks traced from modal velocity. B. CW doppler spectrum, homogenous and uniform with tracing done from the outer border to include all velocities

In aortic stenosis PEDOFF probe should always be used, recording gradients from all the windows and not just from apical position. In 100 patients of aortic stenosis recording gradient from various windows, Jeremy $\mathrm{J}$ et al showed that in $61 \%$ of patients, maximum gradient was recorded from right parasternal window (due to angulation) and $23 \%$ of patients were mis- classified if non-apical windows were not recorded. ${ }^{22}$ In cases with peak velocity less than $3 \mathrm{~m} / \mathrm{s}$ a combined imaging and doppler probe can be used.

F. Tissue Doppler: As tissue movement is of low velocity $(<20 \mathrm{~cm} / \mathrm{s}$.) and high amplitude, this modality suits best. The basic pre-requisites are the same as for PW doppler, additional points for quality control are:

1. The ultrasound beam aligns parallel to the ventricular wall.

2. Sample volume size ranges from $5-10 \mathrm{~mm}$ in axial direction.

3. Sampling should start from the junction of myocardium and the respective annulus.
4. Depth should be set to include only a small part of atrium along with the whole ventricle.

5. Gain and filter should be set low.

6. Graphic records are obtained during quite breathing or held expiration.

For a complete TTE study the recommended number of clips and images are 53 and 52 respectively. ${ }^{23}$

STUDY ANALYSIS: This is the job of an experienced and well-trained cardiologist. After acquainting with the preliminary data, the first task is to assess the technical quality of record. The measurements of the structures have been well outlined in the appendix of their recommendations for a standardized report in adult echocardiography by Gardin JM et al. ${ }^{24}$

A recorded study can be analyzed in the following way.

CHAMBER QUANTIFICATION: Should be done according to the guidelines of established authorities. Dimensions are taken either directly from 2D images (preferred) or from 2D directed M-mode tracings. Measurements in M-mode are done by leading edge to leading edge method and in 2D inner edge to inner edge method. Volumes are measured by $\mathrm{Bi}$-plane Simpson's method. Ventricular functions are also assessed by various parameters as detailed below.

1-Left Ventricle: In M-mode distances are measured just below the tips of Mitral valve leaflets, for LV enddiastolic and end-systolic dimensions, Figure 4.

LV mass should be measured according to Devereaux formula, having prognostic value and wealth of clinical evidence. ${ }^{25}$

$$
\begin{aligned}
& \text { LV mass }=0.8\left(1 . 0 4 \left([\text { LVIDD + PWTD + IVSTD }]^{3}-\right.\right. \\
& \left.[\mathrm{LVIDD}]^{3}\right)+0.6 \mathrm{~g}
\end{aligned}
$$

Difference of $15 \mathrm{~g}$ can occur if there is an error of 1 $\mathrm{mm}$ in measurement of $\mathrm{LV}$ wall thickness. ${ }^{26} 2 \mathrm{D}$ formulae can also be used. Relative wall thickness is measured either by dividing the sum of septum and posterior wall by LV end diastolic diameter or using the formula $2 \mathrm{X}$ LVPW/LVEDD to avoid problems of sigmoid and paradoxic septum. ${ }^{27}$ Based on LV mass and RWT four patterns of LV hypertrophy are reported By Ganau A et al in hypertensive subjects. ${ }^{28}$

LV volume measurements are done by biplane Simpson's method, figure 4B. These are especially useful for small and large body sized subjects particularly in females for valvular regurgitation. Endocardial border is traced between the compact myocardium and blood pool with trabeculae and 
papillary muscles, counted as part of the volume of cavity, Figure 4C.
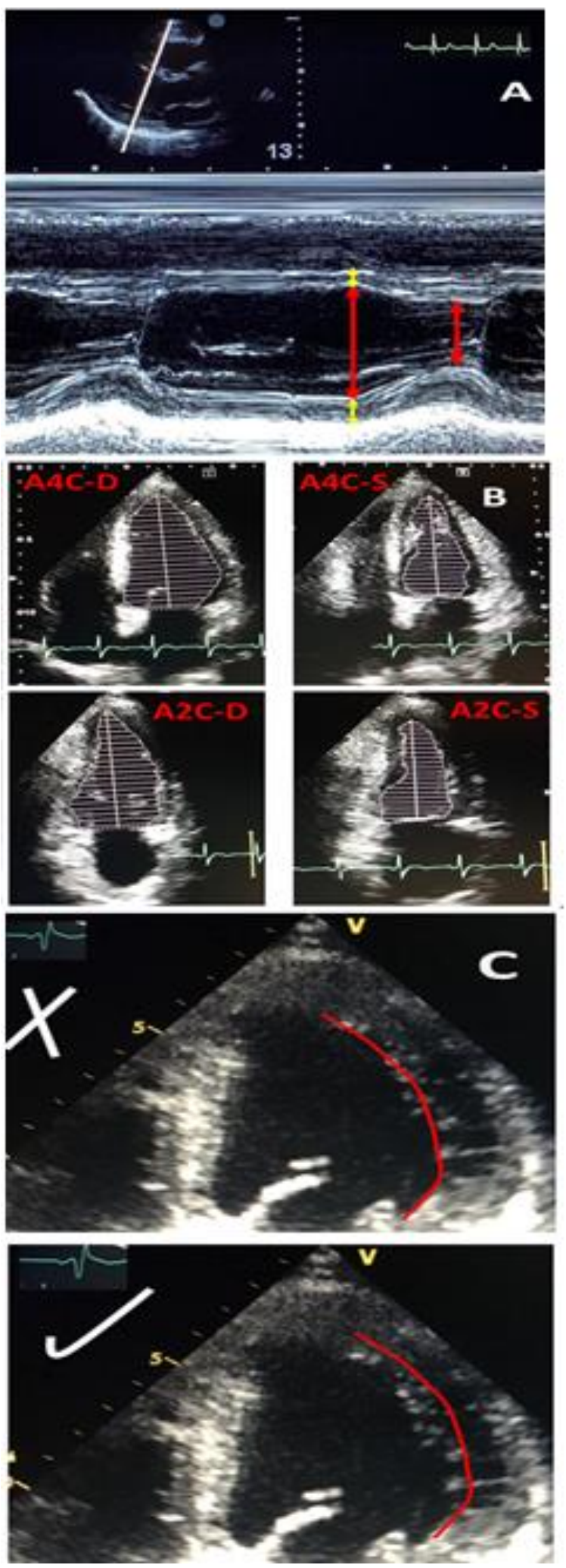

Figure 4: A. M-mode directed 2D method for measurement of ventricular septum, left ventricle posterior wall (yellow arrows), diastolic and systolic dimensions (red arrows). B. LV volume measurement by bi-plane Simpson's method. C. Tracing of endocardial border between blood pool and compacted myocardium

2-Right ventricle: Measurements are taken in RV focused apical view with maximal expansion of RV cavity and no fore-shortening of length. Apical trabeculum should be included in area measurement. Basal and mid diameter along with the length are measured, Figure 5. TAPSE and TDI measurements need precautions as previously explained.
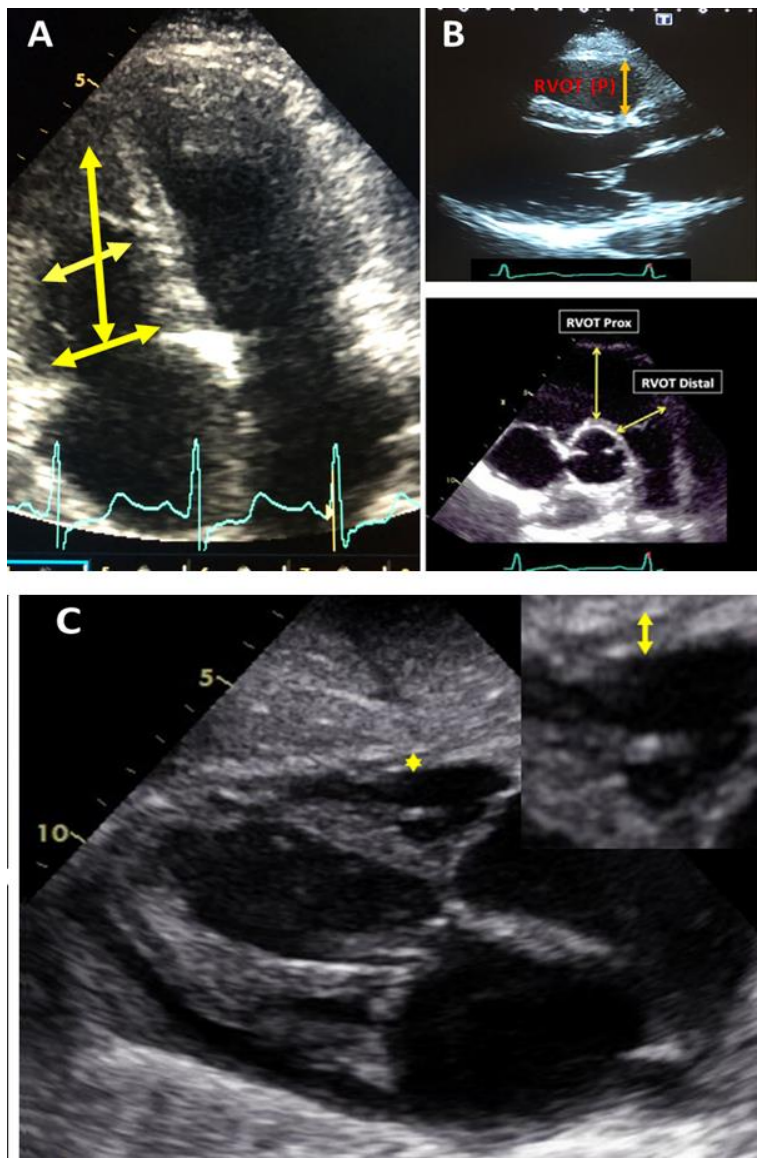

Figure 5: Right ventricle measurements. A-A4C RV directed view showing the three RV measurements, B-PS long and short axis views showing RVOT measurement proximal and distal and C- sub-costal view showing $R V$ free wall measurement (yellow arrow)

3-Left atrium: Dimension should be measured in 2D parasternal long axis (PS LAX) view from aorta to left atrial posterior wall (at aortic sinus level), preferred method or in $\mathrm{M}$ mode. For volume measurements apical 4 and 2 chamber views are utilized, tracing the 
endocardial border and excluding the confluence of pulmonary veins and LA appendage, Figure 6.
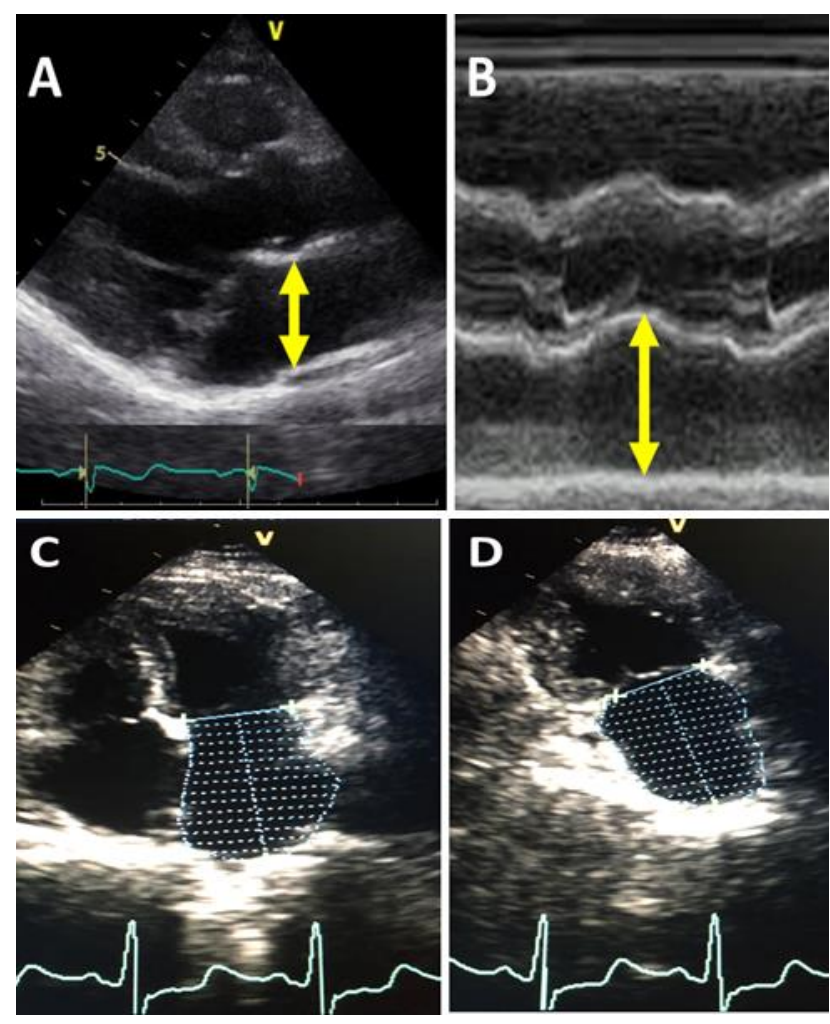

Figure 6: Left atrium. A and B; Diameter C; Volume measurement

4-Aorta: Measured in 2D PS LAX view either by 2D or $M$ mode in zoom mode. Annulus is measured in mid-systole (at hinge points of right coronary sinus and the junction of left and non-coronary sinus) whereas, sinu-tubular (ST) junction and ascending aorta measured at end diastole, Figure 7.
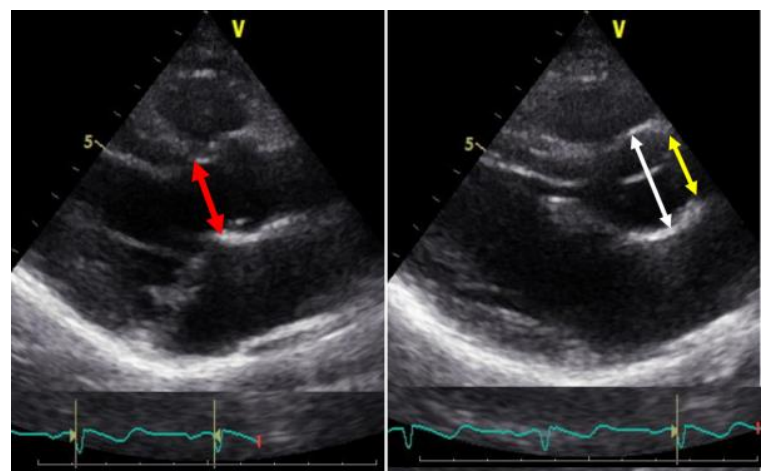

Figure 7: Aortic measurements, annulus (red arrow), sinus portion (white arrow) and ST junction (yellow arrow)
5-Right atrium: Measured in RV focused view with no foreshortening and base maximally expanded at end systole from mid interatrial septum to lateral wall. Area is traced along inner lining excluding area under TV annulus and RA appendage, Figure 8A.
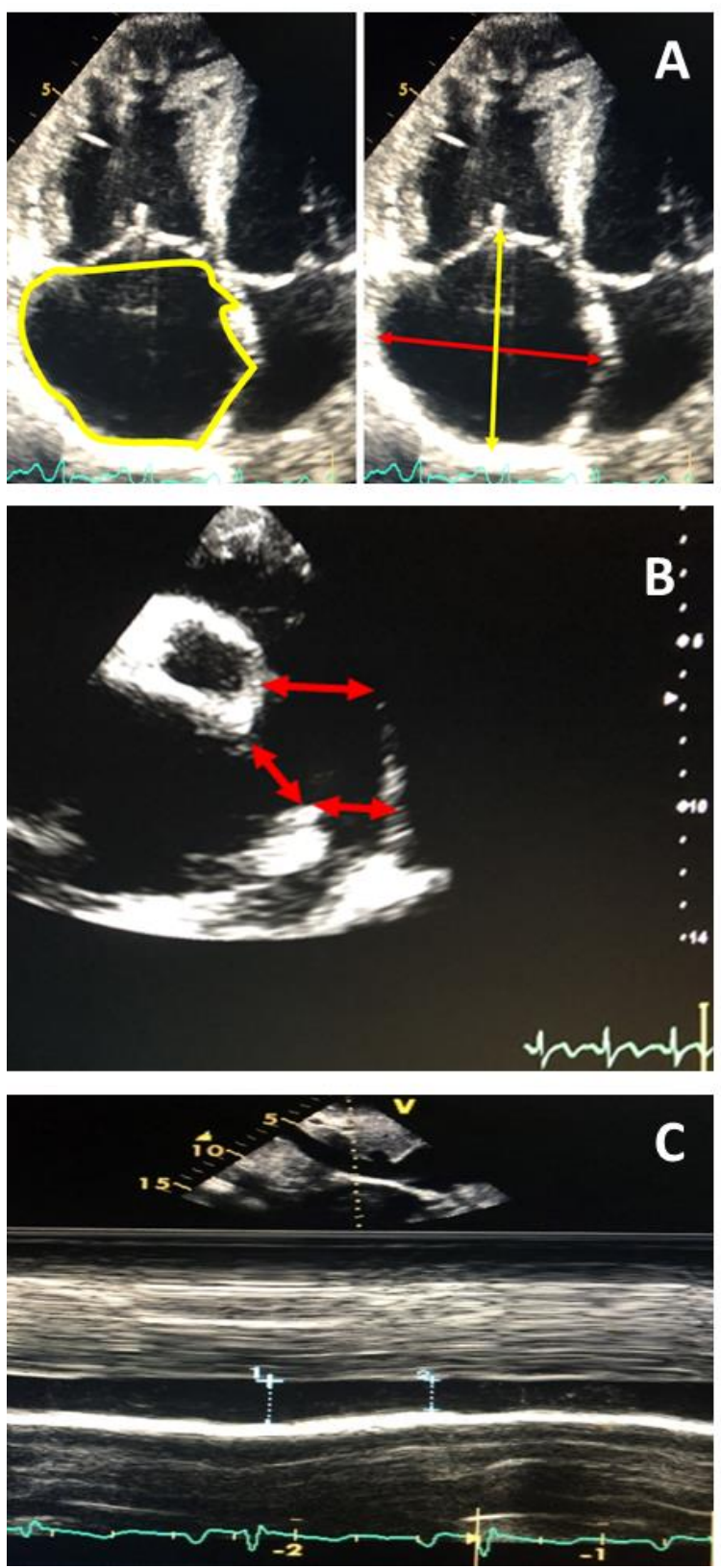

Figure 8: A: Right atrial dimensions and area. B: Main and branched pulmonary arteries. C: Inferior vena cava

6-Inferior vena cava: Measured $1-2 \mathrm{~cm}$ distal to opening in right atrium, collapsibility with respiration also noted, figure $8 \mathrm{C}$. 
7-Pulmonary artery: Main Pulmonary artery is measured at end diastole at mid- point in PS SAX view and branches are measured at ostia, figure $8 \mathrm{~B}$.

8-Pulmonary Vein: Recorded in A4C view and also in Supra-sternal SAX view (Crab's view), especially for flow velocities.

For functional assessment of ventricles, valvular disease, pulmonary artery pressure assessment and conclusion reader is referred to part B of the article under same head.

\section{AUTHORS' CONTRIBUTION}

$\mathrm{IH}$ : Concept and design, data acquisition, interpretation, drafting, final approval, and agree to be accountable for all aspects of the work.

Conflict of interest: Authors declared no conflict of interest.

ACKNOWLEDGEMENT: Thanks are due to Ms Huffsa Imran for typing and proof reading the manuscript. She also helped in designing the images.

\section{REFERENCES}

1. Douglas PS, Garcia MJ, Haines DE, Lai WW, Manning WJ, Patel AR, et al ACCF/ASE/AHA/ASNC/HFSA/HRS/SCAI/SCCM/SCCT/SC MR 2011 Appropriate Use Criteria for Echocardiography. A Report of the American College of Cardiology Foundation Appropriate Use Criteria Task Force, American Society of Echocardiography, American Heart Association, American Society of Nuclear Cardiology, Heart Failure Society of America, Heart Rhythm Society, Society for Cardiovascular Angiography and Interventions, Society of Critical Care Medicine, Society of Cardiovascular Computed Tomography, and Society for Cardiovascular Magnetic Resonance Endorsed by the American College of Chest Physicians. J Am Coll Cardiol. 2011;57(9):112666.

2. Clinical indications for echocardiography. British Society of Echocardiography.

3. https://www.bsecho.org/common/Uploaded\%20files/Education/ Protocols\%20and\%20guidelines/Indications\%20for\%20echocard iography.pdf

4. Ingram TE, Baker S, Allen J, Ritzman S, Bual N, Duffy L, et al. A patient centered model to quality assure outputs from an echocardiography department: consensus guidance from the British Society of Echocardiography. Echo Res Pract. 5:4;2018.G25-G33

5. Kossaify A, Grollier G. Echocardiography practice: insights into appropriate clinical use, technical competence and quality improvement program. Clinical Medicine Insights: Cardiology. 2014;8:CMC-S13645

6. Steeds RP, Garbi M, Cardim N, Kasprzak JD, Sade E, Nihoyannopoulos P, et al. EACVI appropriateness criteria for the use of transthoracic echocardiography in adults: a report of literature and current practice review. Eur Heart J Cardiovasc Imaging. 2017;18(11):1191-204.

7. Al-Kaisey A, Jones E, Nadurata V, Farouque O, De Silva D, Ramchand J. Appropriateness use of echocardiography in an Australian Regional Centre. Intern Med J. 2015;45(11):1128-33.

8. Patil HR, Coggins TR, Kusnetzky LL, Main ML. Evaluation of appropriate use of transthoracic echocardiography in 1,820 consecutive patients using the 2011 revised appropriate use criteria for echocardiography. Am J Cardiol. 2012;109(12):1814-7.

9. Rameh V and Kossaify. Appropriate Use Criteria in Echocardiography: An Observational Institutional Study with the Perspective of a Quality Improvement Project. Clinical Medicine Insights: Cardiology 2016:10;23-8.

10. Matulevicius SA, Rohatgi A, Das SR, Price AL, Deluna A, Reimold SC. Appropriate use and clinical impact of transthoracic echocardiography. JAMA Intern Med. 2013;173(17):1600-7.

11. Gurzun MM and Ionescu A. Appropriateness of use criteria for transthoracic echocardiography: are they relevant outside the USA? Eur Heart J Cardiovasc Imaging. 2014;15:450-55.

12. Pfaffenberger S, Bartko P, Graf A, Pernicka E, Babayev J, Lolic E, et al. Size Matters! Impact of Age, Sex, Height, and Weight on the Normal Heart Size. Circ Cardiovasc Imaging. 2013:6;1073-9.

13. Ritzmann S, Baker S, Peck M, Ingram TE, Allen J, Duffy L, et al. British Society of Echocardiography Departmental Accreditation Standards 2019 with input from the Intensive Care Society. Echo Res Pract. 2020;7(1):G43-9.

14. Thomas JD, Adams DB, DeVries S, Ehler D, Greenberg N, Garcia $\mathrm{M}$, et al. Guidelines and recommendations for digital echocardiography: a report from the Digital Echocardiography Committee of the American Society of Echocardiography. J Am Soc Echocardiogr. 2005:18;287-97.

15. Ryan T, Berlacher, Lindner JR, Mankad SV, Rose GA, Wang A. COCATS 4 Task Force 5: Training in Echocardiography Endorsed by the American Society of Echocardiography. J Am Coll Cardiol. 2015:65(17);1786-99.

16. Price S, Via G, Sloth E, Guarracino F, Breitkreutz R, Catena E, et al. Echocardiography practice, training and accreditation in the intensive care: document for the World Interactive Network Focused on Critical Ultrasound (WINFOCUS) Cardiovasc Ultrasound. 2008 Dec;6(1):1-35.

17. Wiegers SE, Ryan T, Arrighi JA, Brown SM, Canaday B, Damp JB, et al. 2019 ACC/AHA/ASE advanced training statement on echocardiography (revision of the 2003 ACC/AHA clinical competence statement on echocardiography): a report of the ACC Competency Management Committee. Developed in collaboration with the American Thoracic Society, Society for Cardiovascular Angiography and Interventions, Society of Cardiovascular Anesthesiologists, and Society of Critical Care Medicine. Circ Cardiovasc Imaging. 2019:12;e000026.

18. Picard MH, Adams D, Bierig SM, Dent JM, Douglas PS, Gillam LD, et al. American Society of Echocardiography Recommendations for Quality Echocardiography Laboratory Operations. J Am Soc Echocardiogr. 2011:24(1);1-10.

19. Kinsara AH, Ghazal S, Omran AS and Aleid E. The Echocardiography Society of Saudi Heart Association Recommendation on Quality and Laboratory Accreditation Guideline and Standards. J Saudi Heart Assoc. 2020:32;298.

20. Mansi IA, Slim AM. Echocardiography. Available at: https://emedicine.medscape.com/article/1820912-overview

21. Shapira JN, Harold JG. Two-Dimensional Echocardiography Cardiac Doppler, Second Edition. Chapter 5, Nomenclature, Image Orientation and Anatomic-Echocardiographic Correlations with Tomographic Views. Seward JB, Tajik AJ, Hagler D and Edwards WD. Pp68-120 Publisher William and Wilkins 1990

22. Zoghbi WA, Adams D, Bonow RO, Sarano ME, Foster E, Grayburn PA, et al. Recommendations for Noninvasive Evaluation of Native Valvular Regurgitation A Report from the American Society of Echocardiography Developed in Collaboration with the Society for Cardiovascular Magnetic Resonance. J Am Soc Echocardiogr 2017:30(4);303-71.

23. Thaden JJ, Nkomo VT, Lee KJ, Oh JK. Doppler Imaging in Aortic Stenosis: The Importance of the Non-apical Imaging Windows to Determine Severity in a Contemporary Cohort. J Am Soc Echocardiogr. 2015:28;780-5.

24. Mitchell C, Rahko PS, Blauwet LA, Canaday B, Finstuen JA, Foster MC, et al. Guidelines for Performing a Comprehensive Transthoracic Echocardiographic Examination in Adults: 
Recommendations from the American Society of Echocardiography. J Am Soc Echocardiogr. 2018:32(1);1-64.

25. Gardin JM David B. Adams DB, Douglas PS, Feigenbaum H,

Forst DH, Fraser AG et al. Recommendations for a standardized report for adult transthoracic echocardiography J Am Soc Echocardiogr. 2002;15(3):275-90.

26. Devereux RB, Alonso DR, Lutas EM, Gottlieb GJ, Campo E, Sachs I, et al. Echocardiographic assessment of left ventricular hypertrophy: comparison to necropsy findings. Am J Cardiol. 1986:57;450-8.
27. King DL. Three-dimensional echocardiography: use of additional spatial data for measuring left ventricular mass. Mayo Clin Proc. 1994:69;293-5.

28. Marwick TH, Gillebert TC, Aurigemma G, Chirinos J, Derumeaux G, Galderisi M, et al. A Report from the European Association of Cardiovascular Imaging (EACVI) and the American Society of Echocardiography (ASE). J Am Soc Echocardiogr. 2015;16(6):577-605.

29. Ganau A, Devereux RB, Roman MJ, Simone GSD, Pickering TJ, Saba PS et al. Patterns of Left Ventricular Hypertrophy and Geometric Remodeling In Essential Hypertension. J Am Coll Cardiol. 1992:19(7);1550-8.

\section{Address for Correspondence:}

Dr. Imran Hameed, Anklesaria Nursing Home, Aga Khan III road garden, Karachi, Pakistan.

Email: imranhameed61@ hotmail.com 